УДК 619:616.995.1:636.32/.38

DOI:

Поступила в редакцию: 26.03.2015

Принята в печать: 10.03.2017

\title{
Для цитирования:
}

Глазьев Е. Н., Архипов И. А., Бальшщев А. В., Драгункина О. С., Зубарев В. Н. Эффективность ритрила при гельминтозах мелкого рогатого скота. // Российский паразитологический журнал. - М., 2017. - T.39.- Bыn.1. - C.

For citation: Glaz'ev E. N. , Arhipov I. A. , Balyshev A. V., Dragunkina O. S., Zubarev V.N. Efficacy of Ritril used against helminthiases in small cattle/l Russian Journal of Parasitology, 2016, V. -, Iss. -, pp.

\section{ЭФФЕКТИВНОСТЬ РИТРИЛА ПРИ ГЕЛЬМИНТОЗАХ МЕЛКОГО РОГАТОГО СКОТА}

\author{
Глазьев Е. Н. ${ }^{1}$, Архипов И. А. ${ }^{1}$, Балышев А. В. ${ }^{1}$, Драгункина О. С. ${ }^{2}$, Зубарев В. \\ H. $^{2}$
}

1 Всероссийский научно-исследовательский институт фундаментальной и прикладной паразитологии животных и растений им. К. И. Скрябина, 117218, Россия, Москва, ул. Б. Черемушкинская, д. 28, e-mail: arkhipov@vniigis.ru

${ }^{2}$ ООО «НИТА-ФАРМ», Россия, г. Саратов, e-mail: sr-center@nita-farm.ru

\section{Реферат}

Цель исследования - изучение эффективности ритрила на основе рикобендазола и триклабендазола при основных гельминтозах мелкого рогатого скота.

Материалы и методы. Изучение эффективности ритрила проводили в августе-ноябре 2013 г. при основных гельминтозах овец и коз в частных подворных хозяйствах с. Ушаковка и Козловка Атяшевского района Республики Мордовия, в экспериментальном хозяйстве «Курилово» Подольского района Московской области и в ООО «Юг-Поволжья» Большечерниговского района Самарской области. Подопытных животных разделяли на опытные и контрольные группы. Овцам и козам опытных групп вводили ритрил индивидуально, однократно, внутримышечно, в дозах 0,8; 1,2 и 1,6 мл/10 кг массы животного. Животным контрольных групп препарат не задавали. Антигельминтную эффективность препарата учитывали по результатам исследований проб фекалий животных по типу «контрольный тест» до и через 10-20 сут после применения препарата и гельминтологического вскрытия. Для копрологических исследований использовали метод Бермана и метод последовательных смывов. Проведено гельминтологическое вскрытие печени при исследовании на фасциолез, сычуга и кишечника при стронгилятозах пищеварительного тракта.

Результаты и обсуждение. Ритрил в дозе 0,8 мл/10 кг массы животного показал 98-100\%-ную эффективность при мониезиозе, диктиокаулезе, нематодирозе и других стронгилятозах пищеварительного тракта овец и коз. Более устойчивыми к действию препарата оказались трихоцефалы, дикроцелии, фасциолы (преимагинальные и имагинальные формы), против которых рекомендуется применять препарат в повышенной дозе, т. е. 1,6 мл/10 кг массы животного. Препарат хорошо переносился овцами и козами, не вызывал местных и 
общих побочных эффектов.

Ключевые слова: овцы, козы, гельминтозы, ритрил, рикобендазол, триклабендазол, антигельминтная эффективность.

\section{Введение}

Гельминтозы жвачных животных широко распространены в разных природно-климатических зонах России. Наиболее опасными по тяжести заболевания и сложности лечения являются трематодозы - фасциолез, дикроцелиоз и парамфистоматозы; цестодозы - мониезиоз, тизаниезиоз, авителлиноз; нематодозы - стронгилятозы пищеварительного тракта, диктиокаулез, стронгилоидоз. Часто эти болезни протекают в форме смешанных инвазий.

Своевременное проведение профилактических и лечебных мероприятий по борьбе с гельминтозами животных способствует сохранению поголовья и повышению его продуктивности.

Компания «НИТА-ФАРМ» (Россия) разработала новый инъекционный препарат ритрил для лечебной и профилактической дегельминтизации крупного рогатого скота, овец и коз при трематодозах, цестодозах и нематодозах. Препарат создан на основе рикобендазола и триклабендазола, относящихся к классу бензимидазолов. Рикобендазол, являющийся активным метаболитом альбендазола, имеет широкий спектр антигельминтного действия в отношении половозрелых и неполовозрелых нематод и цестод, половозрелых трематод и обладает овоцидным действием. Триклабендазол эффективен против неполовозрелых и имагинальных фасциол.

Цель нашей работы - изучить эффективность применения инъекционного препарата ритрил при различных гельминтозах мелкого рогатого скота.

\section{Материалы и методы}

Изучение эффективности препарата ритрил проводили с августа по ноябрь 2013 г. при нематодирозе и других стронгилятозах пищеварительного тракта на 40 овцах и 26 козах, при мониезиозе на 20 овцах и 15 козах, при фасциолезе на 36 овцах и 14 козах в частных подворных хозяйствах с. Ушаковка и Козловка Атяшевского района Республики Мордовия, при диктиокаулезе и трихоцефалезе соответственно на 26 и 31 овцах в экспериментальном хозяйстве «Курилово» Подольского района Московской области, при дикроцелиозе на 40 овцах в ООО «Юг-Поволжья» Большечерниговского района Самарской области.

При проведении исследований при каждом гельминтозе животных разделяли на опытные и контрольные группы с соблюдением одинаковых условий кормления и содержания. Овцам и козам опытных групп вводили препарат ритрил индивидуально, однократно, внутримышечно, в дозах 0,8; 1,2 и 1,6 мл/10 кг массы животного. Животным контрольных групп препарат не вводили. Схема эксперимента приведена в таблице 1.

Антигельминтную эффективность препарата учитывали по результатам исследований проб фекалий животных по типу «контрольный тест» до и через 10-20 сут после применения препарата и гельминтологического вскрытия. Для копрологических исследований использовали флотационные методы, метод Бермана и метод последовательных смывов. Учет числа яиц гельминтов определяли в 1 г фекалий [3, 4].

Проведено гельминтологическое вскрытие печени при исследовании на фасциолез, сычуга и кишечника при стронгилятозах пищеварительного тракта (по три головы с группы). Видовой состав нематод устанавливали по определителю $[5]$. 
Таблица 1

Схема проведения эксперимента по изучению эффективности препарата ритрил при гельминтозах мелкого рогатого скота

\begin{tabular}{|c|c|c|c|}
\hline Гельминтоз & Вид животного & $\begin{array}{c}\text { Число животных в группе, } \\
\text { опытной/контрольной }\end{array}$ & $\begin{array}{c}\text { Доза } \\
\text { препарата, } \\
\text { мл/10 кг }\end{array}$ \\
\hline \multirow{2}{*}{$\begin{array}{c}\text { Стронгилятозы } \\
\text { пищеварительного }\end{array}$} & Овцы & $20 / 20$ & \multirow[t]{2}{*}{0,8} \\
\hline & Козы & $14 / 12$ & \\
\hline Диктиокаулез & Овцы & $13 / 13$ & 0,8 \\
\hline Трихоцефалез & Овцы & $8 / 7 *$ & $\begin{array}{l}0,8 \\
1,2 \\
1,6\end{array}$ \\
\hline \multirow[t]{2}{*}{ Мониезиоз } & Овцы & $10 / 10$ & \multirow[t]{2}{*}{0,8} \\
\hline & Козы & $8 / 7$ & \\
\hline Дикроцелиоз & Овцы & $10 / 10^{*}$ & $\begin{array}{l}0,8 \\
1,2 \\
1,6 \\
\end{array}$ \\
\hline \multirow[t]{2}{*}{ Фасциолез } & Овцы & $9 / 9 *$ & $\begin{array}{l}0,8 \\
1,2 \\
1,6 \\
\end{array}$ \\
\hline & Козы & $7 / 7$ & 1,6 \\
\hline
\end{tabular}

Примечание: * - три опытных группы и одна контрольная.

\section{Результаты и обсуждение}

В результате проведенных исследований установлена хорошая переносимость ритрила животными. Каких-либо отклонений от физиологической нормы не отмечали. Результаты наших исследований по определению эффективности препарата ритрил при основных гельминтозах мелкого рогатого скота приведены в таблице 2.

Установлена 100\%-ная эффективность ритрила в дозе 0,8 мл/10 кг массы животного при нематодирозе, 99,23\%-ная - у овец и 98,41\%-ная - у коз при других стронгилятозах пищеварительного тракта.

Через 18 сут после введения препарата все овцы и козы опытных групп полностью освободились от нематодирусов, о чем свидетельствует отсутствие яиц гельминтов в фекалиях животных. Экстенсивность инвазии в контрольных группах сохранялась на прежнем уровне.

Кроме того, проводили учет эффективности по результатам гельминтологических вскрытий сычуга и кишечника выборочно убитых животных. При вскрытии пищеварительного тракта обработанных овец опытной группы нематодирусов и других стронгилят пищеварительного тракта не обнаружили. У животных контрольной группы обнаружили, в среднем, по $123,7 \pm 14,8$ экз. Nematodirus spathiger, $73,5 \pm 9,8$ экз. Haemonchus contortus, $34,2 \pm 4,5$ экз. Bunostomum phlebotomum, 20,5 $\pm 4,4$ экз. Ostertagia ostertagi.

Установлена 100\%-ная эффективность ритрила при диктиокаулезе овец. Через 15 сут после введения препарата овцы опытной группы полностью освободились от диктиокаул, о чем свидетельствует отсутствие личинок нематод в фекалиях животных. Зараженность диктиокаулами овец контрольной группы в период опыта существенно не изменялась. Среднее число диктиокаул составило в 1 г фекалий до опыта 76,3 $\pm 6,2$ и в конце опыта $78,2 \pm 7,0$ экз. 
Таблица 2

Эффективность препарата ритрил при основных гельминтозах овец и коз

\begin{tabular}{|c|c|c|c|c|c|c|c|}
\hline \multirow[t]{2}{*}{ Гельминтоз } & \multirow[t]{2}{*}{$\begin{array}{c}\text { Группа } \\
\text { животных }\end{array}$} & \multirow{2}{*}{$\mid \begin{array}{c}\text { Число } \\
\text { животных в } \\
\text { группе }\end{array}$} & \multirow{2}{*}{$\begin{array}{c}\text { Доза, } \\
\text { мл/10 } \\
\text { кг }\end{array}$} & \multirow{2}{*}{$\begin{array}{c}\text { Освободилось } \\
\text { от инвазии, } \\
\text { гол. }\end{array}$} & \multicolumn{2}{|c|}{$\begin{array}{c}\text { Среднее число яиц/личинок } \\
\text { гельминтов в } 1 \text { г фекалий, экз. }\end{array}$} & \multirow{2}{*}{$\begin{array}{c}\text { Снижение числа } \\
\text { яиц/личинок гель- } \\
\text { минтов в фекалиях, \% }\end{array}$} \\
\hline & & & & & до опыта & после опыта & \\
\hline \multicolumn{8}{|c|}{ Oвųbl } \\
\hline \multirow[t]{2}{*}{ Нематодироз } & Опытная & 10 & 0,8 & 10 & $173,5 \pm 12,2$ & 0 & 100 \\
\hline & Контрольная & 10 & - & 0 & $171,2 \pm 12,6$ & $174,3 \pm 13,0$ & 0 \\
\hline \multirow{2}{*}{$\begin{array}{c}\text { Др. стронгилятозы } \\
\text { пищ. тракта }\end{array}$} & Опытная & 10 & 0,8 & 7 & $194,6 \pm 14,5$ & $1,5 \pm 0,6$ & 99,23 \\
\hline & Контрольная & 10 & - & 0 & $195,2 \pm 14,0$ & $196,3 \pm 14,2$ & 0 \\
\hline \multirow[t]{2}{*}{ Диктиокаулез } & Опытная & 13 & 0,8 & 13 & $77,2 \pm 6,9$ & 0 & 100 \\
\hline & Контрольная & 13 & - & 0 & $76,3 \pm 6,2$ & $78,2 \pm 7,0$ & 0 \\
\hline \multirow[t]{4}{*}{ Трихоцефалез } & Опытная & 8 & 0,8 & 5 & $70,8 \pm 6,8$ & $19,2 \pm 2,4$ & 72,88 \\
\hline & Опытная & 8 & 1,2 & 6 & $68,2 \pm 6,9$ & $12,6 \pm 1,6$ & 81,52 \\
\hline & Опытная & 8 & 1,6 & 8 & $72,8 \pm 6,3$ & $4,6 \pm 0,1$ & 93,68 \\
\hline & Контрольная & 7 & - & 0 & $70,3 \pm 6,6$ & $72,9 \pm 6,9$ & 0 \\
\hline \multirow[t]{2}{*}{ Мониезиоз } & Опытная & 10 & 0,8 & 9 & $179,2 \pm 16,4$ & $2,0 \pm 0,1$ & 98,88 \\
\hline & Контрольная & 10 & - & 0 & $180,6 \pm 14,8$ & $183,4 \pm 16,2$ & 0 \\
\hline \multirow[t]{4}{*}{ Дикроцелиоз } & Опытная & 10 & 0,8 & 1 & $131,2 \pm 9,4$ & $49,0 \pm 5,6$ & 62,65 \\
\hline & Опытная & 10 & 1,2 & 3 & $129,5 \pm 9,2$ & $39,8 \pm 5,2$ & 69,27 \\
\hline & Опытная & 10 & 1,6 & 6 & $128,6 \pm 9,3$ & $19,3 \pm 3,3$ & 84,99 \\
\hline & Контрольная & 10 & - & 0 & $131,6 \pm 9,1$ & $133,9 \pm 9,7$ & 0 \\
\hline \multicolumn{8}{|c|}{ Koзbl } \\
\hline \multirow[t]{2}{*}{ Нематадироз } & Опытная & 7 & 0,8 & 7 & $142,8 \pm 12,8$ & 0 & 100 \\
\hline & Контрольная & 6 & - & 0 & $143,7 \pm 12,2$ & $144,2 \pm 11,8$ & 0 \\
\hline \multirow{2}{*}{$\begin{array}{c}\text { Др. стронгилятозы } \\
\text { пищ. тракта }\end{array}$} & Опытная & 7 & 0,8 & 5 & $144,6 \pm 13,3$ & $2,3 \pm 0,7$ & 98,41 \\
\hline & Контрольная & 6 & - & 0 & $142,2 \pm 12,8$ & $143,8 \pm 12,2$ & 0 \\
\hline \multirow[t]{2}{*}{ Мониезиоз } & Опытная & 8 & 0,8 & 8 & $164,9 \pm 9,8$ & 0 & 100 \\
\hline & Контрольная & 7 & - & 0 & $163,3 \pm 9,6$ & $166,8 \pm 9,9$ & 0 \\
\hline \multirow[t]{2}{*}{ Фасциолез } & Опытная & 7 & 1,6 & 3 & $116,3 \pm 8,7$ & $3,7 \pm 0,7$ & 96,82 \\
\hline & Контрольная & 7 & - & 0 & $117,7 \pm 8,3$ & $118,4 \pm 8,6$ & 0 \\
\hline
\end{tabular}


Эффективность ритрила при мониезиозе овец и коз составила соответственно 98,88 и $100 \%$.

Зараженность мониезиями овец и коз контрольных групп в период опыта существенно не изменялась.

Таким образом, ритрил в дозе 0,8 мл/10 кг массы животного эффективен при мониезиозе, диктиокаулезе, нематодирозе и других стронгилятозах пищеварительного тракта овец и коз.

Ритрил в дозе 0,8 мл/10 кг массы животного оказал недостаточный эффект против трихоцефал $(72,88 \%)$ и дикроцелий $(62,65 \%)$.

Эффективность препарата в дозе 1,6 мл/10 кг при трихоцефалезе составила

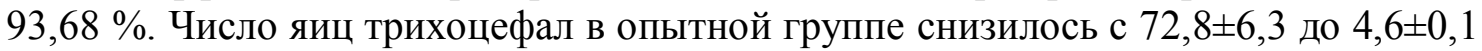
эКз.

84,99\%-ный эффект установлен у ритрила в дозе 1,6 мл/10 кг при

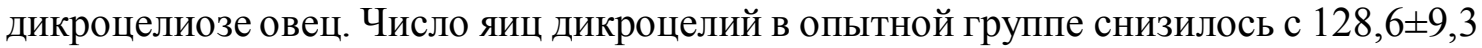
до 19,3 $\pm 3,3$ экз. Зараженность овец дикроцелиями в контрольных группах в период опыта существенно не изменялась.

Против трихоцефал и дикроцелий рекомендуется применять препарат в повышенной дозе, т. е. 1,6 мл/10 кг массы животного.

Результаты изучения эффективности ритрила против фасциол разного возраста приведены в таблице 3.

Таблица 3

Эффективность препарата ритрил при фасциолезе овец по результатам гельминтологического вскрытия печени $(\mathbf{n}=\mathbf{3})$

\begin{tabular}{|c|c|c|c|c|c|c|}
\hline \multirow[t]{3}{*}{$\begin{array}{c}\text { Группа } \\
\text { животных }\end{array}$} & \multirow{3}{*}{$\begin{array}{c}\text { Доза, } \\
\text { мл/10 } \\
\text { кг }\end{array}$} & \multicolumn{3}{|c|}{ Обнаружено фасциол, экз./гол. } & \multirow{2}{*}{\multicolumn{2}{|c|}{$\begin{array}{c}\text { Интенсэффективность } \\
\text { против фасциол, \% }\end{array}$}} \\
\hline & & \multirow[t]{2}{*}{ всего } & \multicolumn{2}{|c|}{ в том числе } & & \\
\hline & & & $\begin{array}{l}\text { неполовоз- } \\
\text { релых }\end{array}$ & $\begin{array}{c}\text { имаги- } \\
\text { нальных }\end{array}$ & $\begin{array}{c}\text { неполовоз- } \\
\text { релых }\end{array}$ & $\begin{array}{c}\text { имаги- } \\
\text { нальных }\end{array}$ \\
\hline Опытная & 0,8 & $7,9 \pm 0,9$ & 3,6 & 4,3 & 70,74 & 75,71 \\
\hline Опытная & 1,2 & $5,2 \pm 0,5$ & 2,7 & 2,5 & 78,05 & 85,88 \\
\hline Опытная & 1,6 & $2,4 \pm 0,1$ & 1,7 & 0,7 & 86,18 & 96,05 \\
\hline Контрольная & - & $30,0 \pm 6,7$ & $12,3 \pm 4,0$ & $17,7 \pm 6,6$ & 0 & 0 \\
\hline
\end{tabular}

При фасциолезе овец и коз ритрил целесообразно применять в дозе 1,6 мл/10 кг массы животного. Эффективность ритрила у овец в этой дозе против неполовозрелых и имагинальных фасциол составила 86,18 и 96,05 \% соответственно. 96,82\%-ный эффект установлен у ритрила при фасциолезе коз.

Известно, что препараты на основе бензимидазолов высоко эффективны для терапии и профилактики гельминтозов разных видов животных и, особенно, жвачных [1, 2, 6, 7]. Действующие вещества ритрила (рикобендазол и триклабендазол) имеют широкий спектр действия на нематод, цестод и трематод, что особенно важно, так как часто в организме животных одновременно паразитируют гельминты разных видов и классов.

\section{Заключение}

Установлен широкий спектр действия ритрила против основных видов нематод, цестод и трематод. Отмечена его высокая антигельминтная эффективность, а также безопасность в применении.

Ритрил в дозах 0,8 и 1,6 мл/10 кг массы животного не оказывает негативного действия на организм овец и коз, не вызывает местных и общих побочных 
эффектов.

Терапевтическая доза препарата ритрил при внутримышечном введении при мониезиозе, диктиокаулезе, нематодирозе и других стронгилятозах пищеварительного тракта овец и коз составила 0,8 мл/10 кг массы животного. Препарат в этой дозе показал антигельминтную эффективность, равную 98-100 \%. Более устойчивыми к действию препарата оказались трихоцефалы, дикроцелии, фасциолы. В связи с чем, против этих видов гельминтов рекомендуется применять препарат в повышенной дозе, т. е. 1,6 мл/10 кг массы животного.

\section{Литература}

1. Абрамова Е. В., Архипов И. А., Абрамов В. Е., Драгункина О. С., Жукова H. Н. Антигельминтная эффективность рикобендазола инъекционного при гельминтозах овец. // Российский паразитологический журнал. - 2014. - № 2. С. $77-82$.

2. Глазьев Е. Н., Архипов И. А., Балышев А. В., Драгункина О. С., Жукова Н. Н. Эффективность препарата ритрил при гельминтозах крупного рогатого скота // Российский паразитологический журнал. - 2014. - № 4. - С.84-90.

3. Ивашкин В. М., Контримавигус В. Л., Назарова Н. С. Методы сбора и изучения гельминтов наземных млекопитающих. - М.: Наука, 1971. - 123 с.

4. Котельников Г. А. Гельминтологические исследования окружающей среды. - М.: Росагропромиздат, 1991. - 105 с.

5. Ивашкин В. М., Орипов А. О., Сонин М. Д. Определитель гельминтов мелкого рогатого скота. - М.: Наука, 1989. - 256 с.

6. Coronado A. Eficacia de Ricobendazole en el control de Fasciola hepatica. Gaceta de Ciencias Vet. 2002. V. 8, № 1. P. 4-7.

7. Steffan P. E., Fiel C. A., Ferreyra D. A. The anthelmintic efficacy of ricobendazole after several treatments in cattle harboring gastrointestinal nematodes // Rev. de Med. Vet. (Buenos Aires). 2000. V. 81, № 2. P. 95-99.

\section{References}

1. Abramova E. V., Arhipov I. A., Abramov V. E., Dragunkina O. S., Zhukova N. N. The anthelmintic efficacy of Ricobendazole injectable against helminthiasis in sheep. Rossiyskiy parazitologicheskiy zhurnal [Russian Journal of Parasitology], 2014, no. 2, pp.77-82. (In Russian).

2. Glaz'ev E. N., Arhipov I. A., Balyshev A. V., Dragunkina O. S., Zhukova N. N. Efficacy of the drug Ritril against helminthiasis in cattle. Rossiyskiy parazitologicheskiy zhurnal [Russian Journal of Parasitology], 2014, no. 4, pp.84-90. (In Russian).

3. Ivashkin V. M., Kontrimavigus V. L., Nazarova N. S. Metody sbora $i$ izucheniya gel'mintov nazemnyh mlekopitayushchih. [Methods for collection and study of helminthes in land mammals]. M., Nauka, 1971. 123 p. (In Russian).

4. Kotel'nikov G. A. Gel'mintologicheskie issledovaniya okruzhayushchey sredy [Helminthological observations of the environment]. M., Rosagropromizdat, $1991.105 \mathrm{p}$. (In Russian).

5. Ivashkin V. M., Oripov A. O., Sonin M. D. Opredelitel' gel'mintov melkogo rogatogo skota [Determinant of helminthes in small cattle]. M., Nauka, 1989. 256 p. (In Russian).

6. Coronado A. Eficacia de Ricobendazole en el control de Fasciola hepatica. Gaceta de Ciencias Vet., 2002, vol. 8, no.1, pp. 4-7.

7. Steffan P. E., Fiel C. A., Ferreyra D. A. The anthelmintic efficacy of ricobendazole after several treatments in cattle harboring gastrointestinal nematodes. 
Rev. de Med. Vet. (Buenos Aires), 2000, vol. 81, no. 2, pp. 95-99.

Russian Journal of Parasitology, 2017, V.39, Iss.1

Received: 26.03.2015

Accepted: 10.03.2017

\title{
EFFICACY OF RITRIL USED AGAINST HELMINTHIASES IN SMALL CATTLE
}

Glaz'ev E. N. ${ }^{1}$, Arhipov I. A. ${ }^{1}$, Balyshev A. V. ${ }^{1}$, Dragunkina O. S. ${ }^{2}$, Zubarev V.N. ${ }^{2}$ 1 All-Russian Scientific Research Institute of Fundamental and Applied Parasitology of Animals and Plants named after K.I. Skryabin, 117218 Russia, 28 B. Cheremushkinskaya St., e-mail: arkhipov@vniigis.ru

$2 «$ NITA-FARM» Ltd. , Russia, Saratov, e-mail: sr-center@nita-farm.ru

\begin{abstract}
Objective of research: To study the efficacy of Ritril based on Ricobendazole and Triclabendazole used for the treatment of main helminthiases in small cattle.

Materials and methods: The efficacy of Ritril was investigated in August-November 2013 against main helminthiases in sheep and goats from private farms «Ushakovka» and «Kozlovka» in Atyashevsky district of the Republic of Mordovia, in experimental farm «Kurilovo» in Podolsk district of Moscow region, and «South of Povolzhye Ltd.» in Bolshechernigovsky district of Samara region. Animal were divided into experimental and control groups. Sheep and goats from experimental groups were intravenously injected with Ritril at a single dose of 0,$8 ; 1,2$ and 1,6 ml/10 $\mathrm{kg}$ of the animal's mass. Animals of the control groups did not receive the preparation. The anthelmintic efficacy of the preparation was estimated according to the results of examination of animal feces by «control test» before and 10-20 days after the drug application and helminthological autopsy. Berman's method and sequential washing techniques were used for coprological investigations. Helminthological autopsy of liver was conducted in fascioliasis; maw and intestines - strongilatoses of gastrointestinal tract.

Results and discussion: Ritril at the dose $0,8 \mathrm{ml} / 10 \mathrm{~kg}$ of the animal's mass showed 98-100\% efficacy against monisiasis, dictyocaulosis, nematodiriasis and other strongilatoses of gastrointestinal tract of sheep and goats. Trichocephales, dicrocoelia, fascioles (preimaginal and imaginal stages) were more resistant to the effect of Ritril. It's recommended, to use a higher dose of preparation against them $(1,6 \mathrm{ml} / 10 \mathrm{~kg}$ of the animal's mass). The preparation is well tolerated by sheep and goats and did not cause any local and common side effects.

Keywords: sheep, goats, helminthiases, Ritril, Ricobendazole, Triclabendazole, anthelminthic efficacy.

(C) 2017 The Authors. Published by All-Russian Scientific Research Institute of Fundamental and Applied Parasitology of Animals and Plants named after K.I. Skryabin. This is an open access article under the Agreement of 02.07.2014 (Russian Science Citation Index (RSCI)http://elibrary.ru/projects/citation/cit_index.asp) and the Agreement of 12.06.2014 (CABI.org / Human Sciences section: http://www.cabi.org/Uploads/CABI/publishing/fulltext-products/cabi-fulltext-material-f rom-journals-by-subject-area.pdf
\end{abstract}

